Portland State University

PDXScholar

$5-24-2019$

\title{
A Lot of Admiration and a Little Bit of Worship: Parasocial Relationships and Young Women
}

Raz Mostaghimi

Portland State University

Follow this and additional works at: https://pdxscholar.library.pdx.edu/honorstheses

Let us know how access to this document benefits you.

\section{Recommended Citation}

Mostaghimi, Raz, "A Lot of Admiration and a Little Bit of Worship: Parasocial Relationships and Young Women" (2019). University Honors Theses. Paper 770.

https://doi.org/10.15760/honors.788

This Thesis is brought to you for free and open access. It has been accepted for inclusion in University Honors Theses by an authorized administrator of PDXScholar. Please contact us if we can make this document more accessible: pdxscholar@pdx.edu. 
A Lot of Admiration and a Little Bit of Worship: Parasocial Relationships and Young Women

\author{
by \\ Raz Mostaghimi \\ An undergraduate honors thesis submitted in partial fulfillment of the \\ requirements for the degree of \\ Bachelor of Arts \\ in \\ University Honors \\ and \\ Communication Studies
}

Thesis Adviser

Ian Lowrie

Portland State University

2019 


\begin{abstract}
This research examines young women's experiences with parasocial relationships (PSR) and how they use media in relation to their PSRs. I intended to determine if young women experienced romantic (PSRR) and platonic PSR in different ways with different goals, if PSR/PSRR impacted young women's beliefs and behaviors, how PSR used social media in relation to their PSR, and if nonfictional and fictional media figures resulted in different goals for the PSR. I recruited Portland State University students who were women between the ages of 18 and 30 for a focus group and follow-up interviews on the subject of their PSRs. I found that young women's PSRs reflected Ball-Rokeach's media dependency goals of orientation, understanding, and play, and that PSRs allowed young women to fulfill what Horton and Wohl refer to as their enacted roles.
\end{abstract}

Keywords: parasocial interaction, parasocial relationships, young women, media system dependency theory

At the age of fourteen, an already emotionally turbulent time for anyone, JB was heartbroken for two months. Her favorite YouTubers, a group of six young men known as O2L, had disbanded. To show her love and support, she drew six tally marks on each wrist, representing each member of O2L. JB said that the breakup was the only thing she talked about for those two months of mourning. Eventually, her friends confronted her: "There was one day where they were like, '[JB], you were saying that like these people care about you like more than anyone in your real life does. And that's not cool,", JB told us. "“We cannot be your friends if you're going to be like this." 'Her love for a group of YouTubers she had never met- and the 
subsequent heartbreak of never seeing them together again — was so intense that it ostracized the friends she had made in school. How could a bond formed via screen eclipse friendships with people she saw nearly every day?

The theory of parasocial interaction is one of the countless attempts by communications scholars to determine how, and to what extent, media affect us. Many theories, such as social cognitive theory and cultivation theory, focus on media's ability to influence the public on topics such as violence and perceived threats. What I have found most interesting about media is their ability to connect with us, the audience, so intimately. We can be emotionally moved by media to the extent that we form relationships to their personae akin to the intimate social relationships we have in our day-to-day lives. Parasocial interaction refers to the one-sided interaction a viewer has when consuming media - such as frustration with a character in a horror movie refusing to back down from the killer, or delight and excitement from watching a favorite musician's new music video. Parasocial relationships (PSR) are the one-sided emotional bonds viewers form with media personae (also referred to as media personas or media figures) both during and after media consumption. For this thesis, I conducted a focus group and various interviews with young women who self-identified as having a parasocial relationship. I found that the data gathered from these interviews differed from my initial expectations. Though they did not fully address my research questions, these interviews gave me insight into other, unexpected aspects of parasocial interaction. In contrast to academic and popular sources painting parasocial relationships as a "trick" that unwitting audiences fall for, the young women interviewed used parasocial relationships as a tool to explore and strengthen various social roles in their lives, such as understanding themselves and their relationship needs, determining how to act and interact, and engaging in creative and social leisure activities. I will begin by providing a 
review of previous research on parasocial relationships, which indicates a need for more qualitative research and provides the theoretical frameworks of audience interaction and media systems dependency. After describing my methods, research questions, and results, I will describe the most relevant findings. I divided the findings into four main themes surrounding PSR: self-awareness and comparison of PSR, transportation and identification, creative hobbies and social bonding, and enacted roles and parasocial influence.

\section{Literature review}

The previous research on parasocial relationships has largely consisted of quantitative surveys and literature reviews. Common themes of this research include the stigma of parasocial relationships, the relationship between parasocial interaction and identification or self-esteem, parasocial interaction and opinion leadership, as well as parasocial romantic relationships and their impacts on perceptions of real-life romantic relationships. I will begin by describing the initial theory of parasocial interaction, then I will provide some empirical studies that test aspects of PSR that are relevant to my research. Then, I will examine a theoretical article about the process of parasocial interaction and review Ball-Rokeach's media systems dependency theory, which lays down an analytical framework for my findings.

Horton and Wohl's seminal 1956 paper introduces the theory of parasocial interaction. They describe parasocial relationships as "the seeming face-to-face relationship with the performer" the viewer experiences when consuming radio, television, or film (1956, p. 215). They explore this phenomenon through what they describe as "personality programs" television shows run by a host that interacts with both the studio audience and viewers at home. Horton and Wohl provide a narrower definition of "media personae" than other scholars in the field: unlike actors, their sole purpose is to cultivate a parasocial interaction or relationship with 
the audience. Horton and Wohl argue that the viewer is also performing, like the media persona, when consuming media, because "the spectator must be able to play the part demanded of him; and this raises the question of the compatibility between his normal self [...] and the kind of self postulated by the program schema and the actions of the persona" (Horton \& Wohl, p. 223). Horton \& Wohl argue that parasocial relationships are contingent on whether the viewer can properly fulfill the role expected of the relationship. These enacted roles "may be an idealized version of an everyday performance"- for example, when a young woman listens to a romantic song by a boy band she may enter the role of the girl about whom the song is written (Horton \& Wohl, p. 225). They are also often vicarious in nature. Although parasocial relationships are driven by a performer, Horton and Wohl imply that there is another performance happening on the audience's end. They must, at the very least, act along with whatever fantasy the media persona is presenting. An even more successful audience performance would involve emotional investment in a program even after watching the program, or slightly adjusting one's behaviors in order to match a beloved character.

Following Horton and Wohl's initial introduction of the theory, there have been many quantitative studies testing various aspects of parasocial interaction and relationships, and some theoretical expansions on the theory. Giles' 2002 literature review of parasocial interaction research, although over a decade old, provides insight into the field that still resonates. Some of the key issues in parasocial research that need clarifying, according to Giles, are differentiating between identification and parasocial interaction, examining how PSIs vary based on the type of media persona, and how PSIs and PSRs develop and impact people as they grow older.

One area of parasocial research explores how consumers accept or reject media messages based on their parasocial relationships. Stehr, Rossler, Leissner, and Schonhardt (2015) found 
that parasocial relationships allow media personalities to become opinion leaders, creating parasocial opinion leadership. Media users assign trustworthy characteristics to personas with whom they have parasocial relationships. Parasocial opinion leaders are able to simplify information, "orient their followers to certain values," and make viewers interested in new topics (p. 991-991). Tukachinsky and Sangalang (2016) found that parasocial interactions encourage reacting to and resisting media effects, yet parasocial relationships do not. Tukachinsky and Sangalang conclude that a parasocial interaction encourages viewers to talk back, while a positive parasocial relationship may encourage the viewer to simply agree with everything said, in concordance with Stehr et al.'s model of parasocial opinion leadership. Perhaps the audience's desire to play along with the role assigned in the parasocial interaction leads to following the media figure's opinion. Interestingly, the participants did not describe changing their opinions for a PSR. They instead claimed they mostly already agreed with their media figures or would recognize when the media figure did something that they disagreed with. I will discuss this in further detail in my findings.

Researchers such as Derrick, Gabriel, and Tippin (2008) specifically test the relationship between parasocial relationships and self-esteem. They propose that parasocial relationships assist those with low self-esteem in forming real-life relationships. They found that the closer a celebrity was to their ideal selves the more they liked them, low self-esteem participants felt more similarity between their real selves and their ideal selves while thinking of their favorite celebrities, and that these effects were unique to parasocial relationships. Derrick et al.'s research suggest that identifying with a media persona can lead to forming a parasocial relationship with them, which in turn can improve self-esteem. Similar to Horton and Wohl's description of the 
audience's vicarious or enacted roles they play in PSI, Derrick et. al's findings imply that parasocial relationships help audiences strive toward their ideal selves.

Enacted roles go beyond one's relationship with oneself, and parasocial relationships often provide a place for audiences and media figures to play the role of romantic partners, though not always in a healthy manner. In a cross-sectional survey geared towards young women reminiscing on teen parasocial crushes, Erickson and Dal Cin (2017) found that those who had parasocial romantic attachments in adolescence had more idealized and heteronormative ideas about romance and a greater desire for passionate romantic love. They claim that this desire has both positive and negative results - on one hand, passionate romantic feelings are an important part of emotional development, but they can have a heavy toll, especially on adolescent and young adult women. Tukachinsky and Dorros (2018) also surveyed teenaged and college-aged women about their parasocial romantic relationships (PSRRs) and found that romantic parasocial attachments correlate with increased desired intensity in romantic relationships and decreased relational satisfaction. These studies suggest that parasocial romantic relationships cultivate intensified - perhaps unrealistic — standards of orthosocial (the opposite of parasocial, interpersonal) romance.

Beyond quantitative inquiries into PSR, another important subfield of previous research has also theorized about the process of audience interaction with media and the levels of PSR intensity. Brown (2015) suggests a model that outlines the levels of parasocial interaction and its relationship to identification. Brown states that there are four consecutive processes in audience interaction with media personas: transportation, parasocial interaction, identification, and worship. Transportation refers to when an individual becomes "emotionally and psychologically involved in both the narrative and with the characters in the narrative" (Brown, p. 262). 
According to Brown, this happens concurrently with parasocial interactions and relationships.

The next level of interaction with media persona is identification, which can lead viewers to adopt the behaviors of their favored media personae — at times unintentionally (Brown, p. 264). The final, most intense level of interaction is worship. Brown uses Maltby's three levels of worship — following the lives of media personas, "intense personal feelings" towards personae, and "mild pathological" obsession (Maltby et al., 2005, p. 1166, as cited in Brown, p. 266). Brown argues that there is a linear relationship between parasocial relationships, identification, and worship and that worship should not be considered part of a PSR. In contrast, Horton and Wohl include very intense, romantic PSRs as part of the PSI umbrella, though they acknowledge it as a more extreme form of PSR. They argue, however, that even less extreme PSRs affect the daily lives of people. For example, reserving a certain time of day to watch a television program is akin to setting aside time to see a friend for lunch.

The one study not directly related to parasocial interaction is a media effects theory that gives insight into what audiences do with media. Ball-Rokeach's media system dependency theory provides a theoretical framework to analyze the media consumption goals of young women with PSRs who participated in the research. Ball-Rokeach's theory posits that "the capacity of individuals to attain their goals is contingent upon the information resources of the media system" (1985, p. 487). She argues that media dependency comes from the media structure of a particular society more than from the needs of an individual. Although she analyzes media on a mass scale, her analysis of the audience is more individually-based. She argues that whereas media are systematic and that mass scale gives them power, audiences are diverse and do not act as a unit, which creates an asymmetrical relationship between the media and their audience. Ball-Rokeach writes that media dependency results in the audience having 
different types of goals when consuming media. She uses the term "goals" because it implies an active audience that have rational objectives for their media behavior. Audience members prioritize and achieve these media dependency goals in differing ways. There are six goals, half of them apply to the audience member's goals on an individual level and the other half apply to the audience member's goals on a social or collective level. The six types of goals are social understanding, self-understanding, action orientation, interaction orientation, social play, and solitary play (Ball-Rokeach, p. 496). This is not an exhaustive list, however. Ball-Rokeach clarifies that audience goals are not the only relevant aspect of media dependency. Media do not fulfill all audience goals, and audience members with the same goals can have different media dependencies. The fulfillment of media dependency goals depends on the specific audience member and attributes of their society's media system.

The literature on parasocial relationship is concerned with defining when and how a parasocial relationship becomes pathological — a concern shared by the focus group participants as well. The previous literature introduces parasocial interaction, shows how audiences adjust their enacted roles to fit the PSR, and tests how that role enactment impacts opinion leadership, self-esteem, and views on romance. This literature informed my methodology, specifically my research questions and sample group, which I will explain in further detail below.

\section{Methods}

From March to May 2019, I recruited participants and conducted focus groups and interviews. I designed and posted flyers asking "Do you love [media figure]? I mean, REALLY love [pronoun]?” The flyers stated that I was a senior in Honors in search of participants for a focus group on parasocial relationships. The requirements for participants included being a female PSU student between the ages of 18 and 30. I wanted to focus on young women for 
several reasons. First, many of the PSRR research focused on young women as a population and I wanted to take a qualitative approach to that research. Second, I also believed it would be easier to find common threads of experiences and stories among participants of a similar age group and gender. Third, I believed that having a focus group where participants had many common demographic factors would garner easier conversation between participants, and they would have more robust conversation from a relatively similar pop-cultural backdrop. It could even mean participants would have PSRs in common and would be able to discuss them with one another. I had four initial research questions that shaped my recruiting process and research questions. I will present each question with interview questions and recruiting choices I made to find answers for said question.

$R Q 1$. Do platonic and romantic parasocial relationships serve different gratifications for young adult women?

I made various copies of the flyers with different media figures. The media figures named were McDreamy, Dana Scully, Harry Styles, Carly Rae Jepsen, the Jonas Brothers, and Mitski, though I specified on the flyers that participants did not have to have a PSR with the named media figure. I aimed to have a mix of well-known media figures who were known for creating parasocial bonds with fans, such as Harry Styles, fictional characters with popular followings, such as Dana Scully, and less mainstream media figures, such as Mitski- who was also the only media figure who was a person of color, as I wanted to include a media figure who was not white. I included media figures that media portray as someone who people often "crush" on, such as the boy band members, because I wanted to determine whether romance factored into the different ways participants underwent PSI and PSRs. 
RQ2: Do platonic and romantic parasocial relationships impact real-life beliefs and behaviors among young women in different ways?

In the focus groups, I used a list of questions that guided certain topics I wanted to explore - such as fantasies, emotions felt during PSR, whether the PSR was romantic or platonic, and whether a PSR had ever influenced participants' opinion on a topic. Though the questions served as a guide, I often would add new questions to probe into participants' answers, and allowed participants to ask me questions as well. I followed up the focus group by having individual interviews with each participant, lasting between 14 and 30 minutes. I also had one hour-long interview with a participant who was not able to attend a focus group. In these more private interviews, I asked participants about more personal feelings about their PSRs and orthosocial relationships in order to see if PSRs affected their expectations of orthosocial interaction and relationships. One theme I wanted to discuss in both a group and individual setting was opinion leadership. I asked questions such as "Has a media figure ever influenced your opinion on a topic?" This was a rather direct way of asking about parasocial influence, but I also probed for more subtle influences, such as Tukachinsky and Dorros' relationship-contingent self-esteem.

$R Q 3$. How does social media impact relational satisfaction in parasocial relationships among young adult women?

In the focus group, I asked participants "Did you use social media to connect with the media figure in any way?" and "Do you still have this connection?" to determine how social media affects how people experience PSR, seeing as it gives new opportunities to connect with media figures and others who share the PSR. I also mentioned social media as a topic on the recruitment flyer, so participants may have known that we would be discussing the topic. 
$R Q 4$. Do fictional and nonfictional parasocial relationships have different causes and impacts for young women?

I included both fictional and nonfictional media personae because I originally intended to explore if parasocial relationships served different needs depending on whether the figure was fictional or not. None of the participants had a strong PSR with a fictional media figure, nor did any potential participants who contacted me. In future research, if I were to further pursue this topic I would mention exclusively fictional PSRs in my recruiting material.

After the focus group and interviews, I transcribed the recordings using the transcription software Temi and then made my own edits to the automated transcript. I read through each transcript multiple times to take notes and code recurring themes. Though I originally intended to code for themes based on my research questions, after holding the interviews I realized I would have to take a more inductive approach and instead look for themes that I noticed in the actual interview process. Participants would voluntarily email me to request to participate, and I would respond by asking for available times and demographic information, including race, age, and sexuality.

\section{Participants and results}

The initial focus group participants were three white women between the ages of 18 and 21. Two identified as bisexual and one identified as heterosexual. The participant who only participated in an interview was a 20-year-old young woman who was self-identified as "mixed Black and white" and heterosexual. None of the participants had a significant PSR with a fictional media figure, meaning I cannot address RQ4. None of the focus group participants described their PSR as romantic, therefore my discussion does not prioritize RQ1. Though these 
questions served as guides for leading discussion, the resulting conversation follows different themes.

\section{Findings and discussion}

In the following sections, I break down the recurring themes in the group and individual interviews. I begin by describing the participants' various forms of self-awareness about their PSRs. This includes usage of the word "obsession" and its relationship to Brown's concept of worship, participants having an epiphany about the fantasy-based nature of their PSR becoming too intense, and using social media and interpersonal interaction to determine when and how behaviors relating to PSRs and PSI are appropriate. Participants' self-awareness about their parasocial relationships show they use their PSR, orthosocial interaction, and social media to determine appropriate behaviors and interactions with others both in the context of PSR and in the social world. This aligns with the media dependency goals of action and interaction orientation.

The second theme revolves around participants' transportation into media and identification with media figures. They described heavily empathizing with media figures and discussing them as if they knew the figures' personalities. This use of PSR echoes the media dependency goals of self and social understanding. The third theme is participants' use of creative hobbies and social activities in relation to their PSR, almost as a means to "talk back" to the media figure and foster orthosocial bonds at the same time. This is evident of the media dependency goals of solitary and social play. The final theme I found was enacted roles and PSR as an aspirational tool. Participants used their PSR in relation to their goals and certain roles they wanted to play in life, though not always in a healthy manner. Using PSR as a means to fulfill 
certain roles or goals also aligns with the media dependency goals of action and interaction orientation.

Stigma, obsession, self-awareness, comparison, and social media

The majority of participants were self-aware about the stigma of parasocial relationships. They would often describe "extreme" examples of PSR as a means of self-comparison and an example of behavior to avoid, but occasionally they would admire people with more intense PSR. Participants frequently used the word "obsession," but each participant had a different relationship with the term, which indicates that Brown's definition of worship may be simultaneously too narrow yet also overlap too much with more normative PSRs. MM said she was "very obsessed" with Lana Del Ray in her high school years, though it has "calmed down quite a bit" now that she is a college student. For her, the most intense phase of her still ongoing PSR with Lana Del Ray had passed. She recalled making large collages of Lana Del Ray and other magazine clippings in her high school years, placed over her bed, and then returning home from college and realizing that she wanted to take all of the collages down.

In contrast, EB often lightheartedly described her PSR with indie musician Mitski as a kind of worship but hesitated to use the word obsession. In the initial focus group, she said, "I know this sounds ridiculous, but I do think of her as a God a little bit. It's a lot of admiration and a little little bit of worship. Just a little, I think a healthy amount though. So it's fine." While MM's PSR was more intense in her past, EB's PSR is still occurring with the same level of intensity. In his typology of audience interaction with media figures, Brown argues that worship should not be considered an aspect of PSR. He cites Maltby et al.'s (2005) three levels of celebrity worship: low-level (following celebrities' lives and discussing them with friends), medium-level (believing the celebrity is one's soulmate), and high-level (a pathological 
obsession) (Brown, p. 266). Brown argues that worship involves adjusting one's life around a media figure, and is too intense to be included under the PSR umbrella. Findings from both my own participants' experiences and previous literature, however, counter this idea. Although EB herself describes her PSR with Mitski as worship, her parasocial interaction with Mitski does not align with previous definitions of worship. She does not follow Mitski on social media or attempt to know more about her personal life, and the conversations she has with people in real life do not revolve around Mitski's personal characteristics — instead, she prefers discusses the lyrics and content of Mitski's music and how she deeply connects with her music. Citing Heinich (2014), Brown notes that worship is a direct result of celebrity culture encouraging celebrity cults (p. 266). Yet, as an independent artist, celebrity tabloids and mainstream popular culture do not promote a "cult" for Mitski by trying to stir public interest in her personal life. Additionally, adjusting one's life for a PSR is not abnormal for a PSR - Horton and Wohl write that setting aside time to watch a favorite program is an example of adjusting one's life around a PSR, though that is a milder example (p. 233). When a PSR exists outside of more conventional media system, it seems that it does not follow theoretical models of PSR and worship as easily.

The pathological implications of this definition of "worship" ignore the fact that all of the participants were self-aware of the oddities of their PSRs, even joking and laughing about it. At the beginning of her PSR, EB tried to frame her relationship to Mitski as one of romantic attraction, which is the most popular depiction of PSR. She clarified in her follow-up interview:

I sometimes I would try uh, I feel like to frame my, I don't want to say obsession, but like my, my, uh, fixation on her, I would try to frame it romantically so I would uh, try to imagine like us, like being in love and like holding hands and smoochin' and stuff. And then I'd be like, 'that's not quite the way that this is going.' 
There are two interesting observations to glean from this quote: firstly, EB (and others in the focus group) were aware of typical expectations and depictions of a PSR, which may explain why EB initially believed her PSR to be a PSRR. Secondly, EB does not want to use the word "obsession" to describe her PSR, perhaps due to its negative connotation.

$\mathrm{AD}$ was one of the few participants who actually had the stereotypical parasocial romantic relationship, which she usually referred to as a crush. She had parasocial crushes on Kendall Schmidt of the boyband Big Time Rush from 2011-2014 and Niall Horan of the boyband One Direction from 2014-2016. She mentioned others in her life labeling her PSRRs as an obsession, but like MM, also self-described the PSR as an obsession. "[My friends and family] knew I had a huge crush on, on Niall so they would just call it an obsession because I love talking about him and One Direction so much," AD said in her interview. She later stated, "I, I have a huge interest and probably obsession with boy bands in general." Again, like MM, her PSRs were more intense in the past, and her self-reflection may lead her and MM to be more comfortable describing the more intense phases of their PSRs as obsessions. She described once investigating whether a local boy band member lived in Portland, Oregon or Vancouver, Washington. By looking through his social media and finding a picture in a local restaurant, she was able to successfully determine his hometown and planned to visit there with a friend in hopes of running into him, but she learned he recently moved away. This incident is the most akin to Brown's definition of worship, as AD regularly followed his life and actively sought out contact.

Despite this example, which some may regard as extreme, AD was self-aware of the onesided aspect of her PSR. She recalled having a "rollercoaster"-like relationship with her PSRs when she was younger: on one hand, she believed she could someday meet Kendall Schmidt and 
"some spark could happen." On the other hand, she knew the odds were against her and he likely would regard her as just a fan. When she was fourteen, she described having a realization that she was too young for Kendall and that he would end up with someone else as a romantic partner. "So then I remember like kind of crying over that and I was like, 'oh my gosh, this is insane. Like I'm crying over this person that I've never met,"' she said. "And I was like, 'I don't want to be this far deep into it ever again.'" This moment became an epiphany for AD, where she realized the emotional limits of a PSR and the risk of taking one too far. This story echoes our initial story with JB: taking a PSR too far led to an emotional breakdown and a subsequent weakening of the PSR, in JB's case with an intervention from her orthosocial bonds. Many of the participants had moments where they realized their feelings were too intense. It seems that despite the one-sided nature, parasocial relationships must have some form of boundaries in order to be healthy, much like an orthosocial relationship. The easiest way to establish this boundary, for most participants, was to remind themselves of the one-sided, fantasy-based nature of the relationship.

Another way this self-awareness about parasocial relationships manifested was through participants' comparison between themselves and others with PSRs. I coded two main themes surrounding self-awareness and comparison: discussing extreme examples of more intense PSRs and having a more intense PSR as a form of social capital. During the focus group, the participants began to discuss various examples of people taking extreme action on their PSRs. JB and MM discussed the intense Twitter debates that people typically have on their "stan accounts." A "stan account," as the participants explained, is an alternate social media profile, separate from a personal account, that is solely dedicated to one's PSR or fandom of choice. JB told us that after One Direction's split, stan accounts that preferred one member would argue 
with those who preferred another member of the band. Another topic of debate among these accounts is the Larry "ship." A "ship," short for relationship, is a pair of media figures that fans would like to see as a couple or is already recognized as a couple within the media. Ship can also be used as a verb - to "ship" two media figures together means that one wants to see the two figures become a romantic couple. While more common among fictional media figures, shipping nonfictional media figures is also a phenomenon.

As JB said, some believe these ships violate media figures' privacy and boundaries. "And there's also people created a- when they were in the band - a ship between Harry and Louis," she says. "[...] So that's, some people are like, 'no, you like ruin their friendship.' So there's a lot of Larry drama." Though this behavior may be akin to orthosocial (opposite of parasocial, interpersonal) gossip about potential romantic relationships within a friend group, there is conflict among those who have PSRs with One Direction members as to whether shipping is appropriate given the considerable social distance between the band and the fans. By using social media, participants could determine whether they were expressing their PSRs appropriately, with social media providing many examples of PSR gone "too far."

Discussing more extreme PSRs indicated that participants knew when a PSR was going too far by violating the boundaries or privacy of the media figure. Some other examples they discussed were One Direction fans hacking into Harry Styles' mother's iCloud account to find pictures of Harry, finding and posting Lana Del Ray's unreleased music, a girl stealing Harry Styles' credit card, and a stalker threatening Lana Del Ray on Facebook before a concert. Participants expressed conflicting feelings about their own PSR and empathy for the media figures in these extreme incidents. "It's kind of a hard line to walk when you're so obsessed with someone and you want to like, like know their life but you also like value them as a person and 
know that if you were in that situation you wouldn't want all of these photos and things coming out," JB said. Here we see JB's self-aware usage of the term "obsessed" along with an expression of empathy for the media figure. MM followed JB's comment with a similar opinion.

Like if I were Lana I'd be like, "this is like a really rough demo from like eight years ago. I don't want this out." So that the same time I definitely really want to hear all of these songs cause like, oh my gosh, how exciting it is that it's not just like the five released albums with her label.

"I want to like get a hug from Harry Styles and like tell him how like much he means to me and how cool his music is I want to write music with him [...] but I also understand that he's just like living his normal, normal-ish human life," JB said at a later point.

Though the participants recognize their feelings as intense, they could all point to examples where PSRs are taken to extreme and inappropriate levels. Conversely, however, they took pride in having a more "intimate" relationship with their media figures than others and admired those with a seemingly more intense - but not too intense- PSR. MM mentioned times where she met people who claimed to like Lana Del Rey but had only heard her most popular songs - though she did not judge them, she became aware of her deeper PSR with Lana Del Rey. Recalling a time that she saw Lana Del Rey in concert, MM said "like a lot of people had homemade tee shirts that were like cool collages of the artist of different like lyrics. And I was like, aw, my tee shirt was from her last tour like, I'm not as cool as these people." MM also discussed becoming aware of how intensely people reacted to Lana Del Rey during her live concerts. Since EB's PSR was less common, she did not speak about any instances where someone acted on their PSR with Mitski in an extreme manner and took pride in her strong parasocial bond with Mitski.

"I felt like I was the only one who felt the way I do about Mitski because like, even like I know that she has fans $[\ldots]$ even when I was at the concert, something in me felt like very 
internal," EB said. She recognized that there had to have been others who felt connected to Mitski, but due to the personal nature of her music, the PSR felt very strong. "It's just me and Mitski in this big crazy world. (laughter)" The participants, JB in particular, were interested in quantifying or comparing their level of PSR with others', or finding some kind of way to measure the intensity of PSI and PSR. They also had an interesting discussion on the gendered representation of PSR as a teenage girl's foolish obsession despite the fact that men such as MM's father had intense parasocial bonds with sports figures.

The participants' use of social media to determine acceptable fan behavior and frequent speculation about different levels of parasocial interaction indicate that PSRs are a tool for participants to determine what Ball-Rokeach calls action and interaction orientation. This media goal refers to audiences' desire to know which actions to take as an individual and the best ways to interact with others in a social context. Participants used media from their media persona to process their feelings regarding the parasocial relationship. Their language use - for example, choosing the word "obsession" to describe a previously more intense PSR versus someone else's judgment of their PSR — indicated how they felt about having a PSR and how socially acceptable they believed their PSR was, which aligns with the action orientation goal of media dependency, where individuals seek to find out whether their personal actions are effective and acceptable. Another example of PSRs leading to action orientation is the "breakdown" that some participants had where they realized they had taken a PSR too far and it was affecting their social and emotional life, such as in the case of JB's mourning of O2L and AD crying over Kendall Schmidt. The many comparisons between more and less dedicated fans, including extreme examples of what not to do with a PSR, served the goal of interaction orientation- participants 
learned how to be socially appropriate with their PSRs, primarily by using social media to see examples of inappropriate parasocial behavior.

Brown's definition of worship does not always match with the participants' experiences. This could be because his definition of worship is too narrow, and some of the activities associated with his definition could easily be attributed to a PSR as well, such as investing time into the PSR and discussing the personal life of the media figure. Worship appears to be a finicky and subjective term, but Ball-Rokeach's argument about the audience may explain it. As previously stated, Ball-Rokeach claims that since the audience does not operate systematically, unlike the media, a monolithic approach to finding out the audience's goals in interacting with media is inappropriate. Similar to any type of interaction with media, people engaging in a parasocial relationship may have different goals depending on their social context and individual needs. What one participant defines as worship may be wildly different from another participant's definition.

Transportation, emotional connection, self/social understanding

In order for audience members to have parasocial interactions with media personae or form a parasocial relationship, Brown argues, they must first experience transportation when viewing media content. According to Brown, transportation is when "audiences become emotionally and psychologically involved in both the narrative with the characters in the narrative, and audiences often imagine themselves in the presence of a persona" (p. 262). Having a form of emotional reaction or connection to a media figure leads to parasocial interaction, and all of the participants expressed having some kind of emotional connection to the media figure and the content they produced. 
Participants spoke about their media figures' personality traits as if they knew them, despite knowing they did not. MM described seeing Lana Del Rey grow as a person through listening to her music, from lyrics that romanticize depression to singing about a newfound appreciation for life. "[Harry Styles is] just such like a kind person," JB said. She described sending his tweets to friends who shared the same level of obsession as her and gushing over how nice he was. "It feels very much like a friend. Like when you see him doing something it feels very like, aww, look at my buddy, doing (laughter) a good thing." Harry Styles is one of the more popular former members of One Direction, and evidently, his fans can form very strong parasocial bonds with him. This could likely be due to his ability to exist as a very famous public figure - JB described that he was more cordial with paparazzi than other members of the band. Horton and Wohl claim that a media persona hoping to initiate a successful parasocial relationship with audiences should be kind and personable (p. 220). Styles' ability to make fans such as JB feel as if they are in the presence of a nice and caring person through reading a tweet or watching a video echoes Horton and Wohl's ideas about what makes people attracted to a media persona. JB also described Styles' motto, "treat people with kindness" as being very influential for her. The motto is printed on Styles' clothing merchandise, and JB owns a jacket with the motto printed on the sleeve so it is most visible to her, serving as a personal reminder. She said that in times where she was frustrated with someone, she would remember Styles' motto and found herself having a more understanding attitude toward the other person. Styles may be more naturally kind while under the pressure of being a public figure, but he also markets this aspect of his personality, as seen through his motto and its accompanying merchandise. Media personae can sustain parasocial relationships not just through their media, but also through merchandise that can serve as a physical reminder of the PSR. One aspect of the 
audience experience that Ball-Rokeach does not discuss in much detail is how the viewer is also often a consumer of goods, and media systems operate (in the United States) as part of a capitalist system. Fashion choices inspired by PSR could be deemed a form of social play, though it is just as much about status and profit. Further research could investigate how consumerism intertwines with PSI and PSR in our mass media system in comparison to more public media systems.

EB's descriptions of her experiences listening to Mitski provide a richer understanding of how parasocial interaction aims to captivate an audience. In their analysis of various strategies media personae use to initiate parasocial intimacy, Horton and Wohl write "the persona tries as far as possible to eradicate, or at least to blur, the line which divides him and his show, as a formal performance, from the audience both in the studio and at home" by interacting with the audience, using intimate camera angles, and having a supporting cast that poses as friends with consistent and stylized character traits (p. 219). Horton and Wohl's argument focuses on personality programs where the intention of interacting with the audience is more obvious. Musicians, especially independent artists, are less likely to intentionally stoke parasocial interaction among their listeners, whereas personality programs arguably derive viewers through parasocial interactions and relationships. Yet Brown's transportation and identification and Horton and Wohl's emotional connection are evident in EB's PSR.

When I put her music on, I imagine myself as her or her as myself [...] it's always very singular when I fantasize about Mitski. Like it's not us together, it's us as the same person, [...] Like, I, I sometimes imagine her like going through the motions of like what she's singing about and like, like I create music videos in my head where either I'm the main character, she's the main character, that kind of thing. 
Mitski's music transports her to a state where she is Mitski or Mitski as her, and as Brown writes, establishes the conditions necessary to form a PSR. EB then provides an example of her thought process while listening to Mitski's music.

She has this song crack baby and that one in particular is like, uh, I, I would imagine just like she talks about she has these metaphors throughout the song and I imagine them happening literally. And I imagine like the powerful imagery that, that, that could be captured if it, if, if it was like filmed as, uh, like, um, like if it was happening in real time. So there's like lines such as, I'm just going to quote, it's probably going to be awkward, but like, um, "went to your room thinking maybe you'll feel something, but all I saw was your burning body waiting." And so I would, I imagine myself opening the door to a like, not dreary, but just a, um, a very empty apartment in spirit and in physicality, just empty. And there's one bed and there's like a window across from where the door is and it's like the white sky outside, it's like that kind of day and there's just like nothing. It's quiet. Um, and I opened the door and on the bed there's another me and it's myself. And, um, but like the me that's on the bed is on fire, just like sitting and staring out the window or at the wall that's like next to the window or that the window is in. Yeah. And um, like the me, that's not on fire, opens the door and then the me that's on the bed is just like sitting there waiting, not sure for what but on fire and then like slowly turns around and to see the other me. Um, that's one example and that's just like one line for the whole song, but the, that's what I always picture when that line comes on.

The vivid image in EB's mind is evidence of the transportation process, but the conflation of EB and Mitski indicate what Brown refers to as identification — he cites Cohen's (2001) definition of identification as a viewer merging themselves with the media persona (p. 265). EB's PSR with Mitski has led her to identify deeply with her, despite the fact that Mitski does not usually directly address her audience in her media and her life is not as public as some of the other aforementioned media personae. This PSR likely comes from the personal nature of Mitski's lyrics. EB often emphasized Mitski's ability to capture emotions that EB herself had not been able to describe before, and described taking long walks just to listen to her music and experience emotional reactions to it. This suggests that parasocial relationships do not only come 
from prioritizing the audience or marketing a fantasy, but they can also emerge from artistic appreciation.

Brown, drawing on Livingstone (1998) and Igartua (2010), defines identification as the stage of media involvement where audiences "empathize with and put themselves in the place of a persona and then adopt the persona's beliefs and goals" (p. 264). Though a less intense version of identification, participants would describe incidents that matched this definition.

EB's emotional transportation and subsequent identification when listening to Mitski reflects Ball-Rokeach's media dependency goal of self-understanding. Through listening to lyrics that described emotions she had always felt, EB was better able to define herself and her feelings. Identifying with Mitski gave her a renewed sense of self. JB's PSR with Harry Styles invokes the goal of social understanding. Through admiring his gracious personality and buying his merchandise, JB developed a better understanding of how to interact socially — treating people with kindness became an important value and social goal for her. Through empathizing and identifying with media personas, participants changed and developed their understanding of their identities and social behaviors.

\section{Creative activities and parasocial relationships}

Participants' parasocial relationships often influenced their creative and social activities, fulfilling Ball-Rokeach's media dependency goals of solitary and social play. These, in turn, would help the participants play their enacted roles within their PSRS — which I will address shortly. Much of the previous literature, such as Brown's theoretical article, Erickson and Dal Cin's study on PSRRs, and Stehr et al.'s theorization of parasocial interaction and opinion leadership, paint audience members experiencing PSI or PSRs as passive receptors of the media figure who mold their identities as a response to their PSR. While it is true that participants 
adjust their behavior or beliefs from their PSRs and can struggle with the one-sided aspect of the relationship, they also use PSRs as a means to create their own art or writing and strengthen their orthosocial bonds.

EB created art while listening to Mitski to express the strong emotions she felt from her music. As she puts it:

I sometimes, I... am listening to music and sketching at the same time and like a Mitski song will come on and I can feel it influencing the content and the context of what I'm drawing and then I'll put it on repeat and then just keep going as long as I can carry it out for. So I have a few pages in my sketchbook right now that are just like specific Mitski songs.

She also created mood boards - digital collections of images meant to invoke a certain aesthetic or feeling — inspired by Mitski's songs. MM claimed she was not a particularly artistic person, but she recalled making bracelets that spelled out Lana Del Rey's album titles and the aforementioned magazine collages. As a musician, JB would learn Harry Styles' songs in the practice rooms and created a motivational series of paintings inspired by Justin Bieber during her brief PSR with him. AD is an avid writer, and both wrote and consumed fanfictions about Big Time Rush and One Direction. She was introduced to fanfiction from "imagines"— short stories, usually about boy bands, that would create a fictional scenario where the reader could imagine themselves in an orthosocial relationship with a member of the band. She emailed fanfictions to her friends - or, if the fanfiction had more serious or romantic content, she would write on paper and tear it out of her notebook to give to her friends to avoid having her mother find her writing. She recalled making collaborative, choose-your-adventure fanfictions with her friends, who appreciated her writing.

I used to also do texting fanfiction cause I was so interested in how like fanfictions work and I wanted to do kind of like choose-your-own-destination. So I had my best friend because she liked my fanfictions and like "do you want to do one over text?" So it'd be 
like a scenario would happen or like a story would happen at some point I'd be like, "Oh do you want to go this direction with it or this one?"

She also described discussing fanfictions that she was currently reading with her close friends. Reading and writing fanfiction was an important part of social bonding for AD and her friends. JB also recalled bonding over imagines with her friends - sometimes because the presented scenario was genuinely exciting, other times laughing at especially bizarre scenarios.

Brown's transportation not only induces empathy for the media figure but also prompts the audience member to create something in response. These creative works exist as a form of both parasocial interaction and orthosocial interaction — on one hand, they are an attempt to talk back to the media figure by expressing admiration, but, as shown by AD and JB discussing these creative works with friends, they become a means for people who share a PSR to bond or for friends to support each others' creative work. Participants used PSRs as a form of solitary play by using their favorite hobbies to explore their feelings about the media figure, and they used PSRs as a form of social play to discuss and share these creative works with friends.

\section{Enacted roles, aspirations, and fantasies}

One of the biggest causes and motivations for parasocial relationships, Horton and Wohl argue, is the desire to play out a vicarious role that may be difficult to fulfill in orthosocial interaction. They describe enacted roles as "an exploration and development of new role possibilities, as in the experimental phases of actual, or aspired to, social mobility" or "an idealized version of an everyday performance" (Horton \& Wohl, p. 225). Many participants played out these enacted roles and were aware of the role-playing element of PSI and PSR. Participants based these enacted roles on their career goals, romantic fantasies, or more unconscious impulses. Three of the participants' stories highlight these different categorizations. 
JB, for example, would like to become a professional musician. She explained how her PSR supported her career goals in the focus group:

I would agree with that. I would say like for me personally, it also invokes like inspiration. Like I go to a lot of concerts, um, a lot. And kind of for like career things but also I just like, um, my parasocial relationships and getting to kind of like experience that has like showed me how much I love music and how much I love live music. And now I'm making that part of my like career path. Um, like I did live sound in high school, like that kind of thing. Like it's turned into like very inspirational and very like, um, uh, kind of like a creative output for me is like music and live music, which I wouldn't have known if I didn't have like those parasocial relationships kind of giving me that inspiration.

When listening to Harry Styles' music, JB described listening to it from the perspective of a musician, taking note of the choices he made and using it as inspiration.

But I think like on a musical level, like there's videos of like him in the studio that like he's released. And I see him like working and in that sense that's when I'm like, this is like a one on one - more one on one kind of thing because it's like, 'oh my gosh, that's like how I like to write! And that's so cool that you're doing that type of arrangement and like working with that producer.

Her career aspirations gave her PSR with Harry Styles a special dimension that others with the same PSR may not necessarily have.

AD's parasocial relationships allowed her to enact the role of a romantic partner. She enacted this role through the aforementioned fanfiction and her own personal fantasies about the media figures. In her interview, she described making up scenarios in her mind about her PSRRs as a way to pass the time and enjoy herself.

And I think to go into more detail, to be honest, I remember being at my aunt's and I had imagined Niall being there next to me cause cause I realize I'm like, you know what, I might as well get like more vulnerable with it. Um, I was, I was just wondering like what it would be like if he was like actually there next to me. So I kind of like imagine if Niall was there next to me and I was just like resting on his shoulder. 
For AD, she typically only had PSRRs when she was single and found them beneficial in certain ways compared to orthosocial relationships. She believed that orthosocial romantic relationships would distract her from schoolwork, whereas PSRRs were less time-consuming. All of the participants believed that PSRs were a safer type of relationship that did not require as much effort and obligation and served as a form of practice for future orthosocial relationships. While Tukachinsky and Dorros found that emotionally intense PSRRs correlated with idealized romantic beliefs and Erickson and Dal Cin found that PSRRs correlated with relationshipcontingent self-esteem, neither of these effects were found among participants. While AD had intense PSRRs that led to some worship-like behavior, she did not mention that her relationship status affected her self-esteem. In fact, she had a rather pragmatic approach to her orthosocial relationships - she recognized when a romantic relationship was detrimental to her academics and emotional wellbeing, and did not idealize her romantic partners. Conversely, EB did claim that her new romantic relationship gave her newfound self-esteem, but her PSRs were not romantic in nature. There is a mismatch (at least, in the eyes of previous literature) between participants' enacted roles in PSRs/PSRRs and their attitudes toward orthosocial relationships.

Beyond romantic relationships, enacted roles can include an idealized or romanticized vision of oneself. MM described Lana Del Rey's impact on her relationship to mental health and status. She described listening to Ultraviolence during a time where she was more depressed, and matching the moody lyrics by dressing in darker colors and feeling her depression more intensely. EB felt similarly about her time listening to Lana Del Rey. "I feel like when I like back when I was listening to Lana del Rey and like, early high school, um, I was, I think I would say it'd be like influenced to just, maybe be like, maybe my sadness was justified because it was being romanticized," she said. Lana Del Rey's music and music videos often contain glamorous 
imagery and dark content, often about relationships with older men, which MM felt had influenced her on a subconscious level. Perhaps the most extreme example of a PSR's influence, MM described a brief, traumatic psychotic episode induced by her new medication's side effects. She had limited control of her thoughts and actions and developed a brief crush on an older man whom she flirted with. After she changed medications, she was lucid and no longer felt the same attraction, but was disgusted to find out the man was still flirting with her. She explained her episode's connection to her PSR in her one-on-one interview.

Um, and that definitely would not have happened if I hadn't been constantly listening to like romanticization of like the Lolita story. Especially that's like the main like motif she thinks about like 'daddy' and like that type of stuff all the time. Um, yeah, it's pretty gross when I think back on it.

This incident is an example of what Tukachinsky \& Dorros and Erickson \& Dal Cin are concerned about - young women, influenced by a parasocial relationship and the media figure espousing unhealthy values and ideas, making unsafe relationship decisions. Interestingly— and frighteningly - this self-described media effect happened when the participant had little control over her own actions and may go beyond the realm of social science-based media effects research. Incidents such as these require interdisciplinary research collaboration with scholars of psychology, the field that originally created the theory of parasocial interaction. As a social scientist, I am not academically equipped to examine how MM's PSR affected her mind during a mental health crisis.

From harmless fantasies about walking in the snow with Niall Horan to subconsciously seeking out a whirlwind romance with an older man, each of the participants' enacted roles fulfill Ball-Rokeach's media dependency goals of action and interaction orientation. By playing out vicarious roles through their PSRs, the participants were able to determine what they would like to aspire to and what they looked for in interpersonal relationships. However, their enacted roles 
did not always align with how they behaved in orthosocial relationships, and occasionally had detrimental effects.

\section{Conclusion}

Past research on parasocial relationships has called for more qualitative literature, and this focus group has provided new insight and nuance into the subject of parasocial relationships. Participants used PSR as a means for certain goals — self-understanding, exploring interests and hobbies, creating social bonds, determining social acceptability — but they also felt genuine emotional connections to their media figures akin to orthosocial interaction, just as Horton and Wohl describe. Participants did not passively consume the media figure, however, they described having self-awareness about the one-sided nature of the bond and thought critically about their PSRs and media figures. Some participants also experienced "worship" as Brown described it, others experienced it in more unconventional ways. They viewed PSI/PSRs as an easier type of relationship, with less obligations, but their PSRs did not have significant influence on their expectations of romance. The young women in the interviews fulfilled a variety of goals through their parasocial relationships and the media associated with them. Future qualitative research should examine a different segment of the population - young women are often the focus of parasocial research, but men also experience PSI. Participants mentioned that some gay men had strong PSRs with female musicians, and that their own fathers had PSRs with athletes and sports teams while scoffing at their daughters' media tastes. We should also consider studying specifically fictional media figures to determine the different goals audiences have with fictional PSRs. 


\section{References}

Ball-Rokeach, S. J. (1985) The origins of individual media-system dependency: A sociological framework. Communication Research, 12(4), 485-510.

Brown, W. J. (2015) Examining four processes of audience involvement with media personae: transportation, parasocial interaction, identification, and worship. Communication Theory, 25, 259-283. DOI:10.1111/comt.12053

Derrick, J. E., Gabriel, S., \& Tippin, B. (2008) Parasocial relationships and self-discrepancies: Faux relationships have benefits for low self-esteem individuals. Personal Relationships, 15(2), 261-280. DOI: 10.1111/j.1475-6811.2008.00197.x

Erickson, S. E., \& Dal Cin S. (2018) Romantic parasocial attachments and the development of romantic scripts, schemas and beliefs among adolescents. Media Psychology, 21(1), 111136, doi: 10.1080/15213269.2017.1305281

Giles, D. C. (2002) Parasocial interaction: A review of the literature and a model for future research. Media Psychology, 4(3), 279-305, DOI: 10.1207/ S1532785XMEP0403_04

Horton, D., \& Wohl, R. R. (1956). Mass Communication and Para-Social Interaction. Psychiatry, 19(3), 215-229.

Stehr, P., Rössler, P., Leissner, L., \& Schönhardt, F. (2015). Parasocial opinion leadership media personalities' influence within parasocial relations: Theoretical conceptualization and preliminary results. International Journal of Communication, 9, 982-1001.

Tukachinsky, R., \& Dorros, S. M. (2018) Parasocial romantic relationships, romantic beliefs, and relationship outcomes in USA adolescents: rehearsing love or setting oneself up to fail?, Journal of Children and Media, 12(3), 329-345, DOI: 10.1080/17482798.2018.1463917 
Tukachinsky, R., \& Sangalang, A. (2016) The effect of relational and interactive aspects of parasocial experiences on attitudes and message resistance. Communication Reports, 29(3), 175-188. DOI: 10.1080/08934215.2016.1148750 